\title{
IMPACTOS AMBIENTAIS E DELIMITAÇÃO DA ÁREA DE PRESERVAÇÃO PERMANENTE DO RIO ESPINHARAS NO TRECHO URBANO DE PATOS-PB
}

\author{
ENVIRONMENTAL IMPACTS AND DELIMITATION OF \\ THE PRESERVATION AREA STANDING IN ESPINHARAS \\ RIVER IN THE URBAN STRETCH OF THE CITY OF
} PATOS-PB

\author{
João Batista Alves \\ Universidade Federal de Campina Grande - Campina Grande - PB - Brasil
}

Felipe Silva de Medeiros

Superintendência de Administração do Meio Ambiente da Paraíba - Patos PB - Brasil

\begin{abstract}
Resumo: Este trabalho teve como objetivo apresentar e avaliar a proposta de delimitação da área de preservação permanente - APP do trecho urbano do Rio Espinharas, na cidade de Patos-PB, realizada pela Superintendência e Administração do Meio Ambiente do Estado da Paraíba - SUDEMA/PB, e diagnosticar os principais impactos ambientais. A demarcação foi feita a partir de pontos georreferenciados coletados às margens do rio, bem como a identificação dos principais impactos ambientais. Identificou-se uma variação de largura da calha do rio entre $10 \mathrm{~m}$ e $50 \mathrm{~m}$, devido a impactos e alterações ocorridas no processo de antropização. A delimitação da APP foi de $50 \mathrm{~m}$ a partir da maior largura de calha. Os principais impactos observados foram: retirada da mata ciliar, poluição por lançamento de esgotos e resíduos sólidos, assoreamento, invasão das margens com construções e usos agropecuários. Infere-se, ainda, que ocorre a falta de fiscalização - omissão dos poderes públicos e da própria sociedade local - na busca de soluções para os problemas detectados.
\end{abstract}

Palavras-chave: Rio Urbano. Delimitação. Legislação. Impactos Ambientais.

Abstract: This paper aimed to present and evaluate the proposal of the delimitation of the permanent preservation area (APP) of the urban stretch of Espinharas River in the city of Patos-PB, carried out by the Superintendence and Management of the Environment - SUDEMA - Paraíba and to diagnose the main environmental impacts The demarcation was made from georeferenced points collected on the river, and the identification of the main environmental impacts. It identified a wide variation in the river rail between 10 and 50 meters, due to impacts and changes occurring in the 
anthropic process. The delimitation of PPA was 50 meters from the widest rail. The main impacts observed were: removal of riparian vegetation; pollution by the dumping of sewage and solid waste, siltation, invading of the banks with buildings and agricultural uses. It infers even though the lack of oversight occurs, failure of public authorities and of the local population in the search for solutions to the problems identified.

Keywords: Urban River. Delimitation. Legislation. Environmental impacts.

\section{Introdução}

$\mathrm{Na}$ contemporaneidade, a problemática ambiental tem emergido de forma cada vez mais contundente nas discussões técnicas, científicas, políticas e entre o público leigo de uma forma geral, devido às constantes divulgações dos efeitos devastadores de ações humanas na natureza. Contudo, no âmbito da sociedade, em geral, há um processo de retardamento entre ouvir sobre o assunto, conhecer o problema e o desencadeamento de ações proativas no sentido de mitigar tais problemas. A percepção que se tem, de um modo geral, é de que as reações só ocorrem após os eventos negativos impactantes. 
Segundo Coelho (2001), Impacto Ambiental é o processo de mudanças sociais e ecológicas ocasionado por perturbações no ambiente, tendo relação entre sociedade e natureza, que se transformam diferencial e dinamicamente. Dentre esses, pode-se mencionar a problemática da devastação das matas ciliares em todos os lugares do mundo.

Apesar desse tipo de ambiente ser de grande importância para a civilização, do ponto de vista ambiental, é extremamente frágil, pois diversas interações ecológicas estão ocorrendo nesse ambiente, tais como a dinâmica hidrológica, as relações entre água e flora, a presença de animais selvagens e todas as atividades que envolvem a sociedade humana.

Tendo em vista a importância ecológica desse ambiente e as relações que se estabelecem entre ele e as ações humanas, é relevante examinar detalhadamente os impactos das ações humanas nesses ambientes de matas ciliares. Dessa forma, a proposta do presente trabalho é diagnosticar os impactos ambientais observados no trecho urbano do Rio Espinharas, na cidade de Patos-PB, e discutir sobre proposta de delimitação de APP para esse espaço, proposta pela SUDEMA/PB.

Para nortear este trabalho, segue um conjunto de objetivos a serem atingidos: identificar e caracterizar os principais impactos ambientais encontrados; apresentar e avaliar a proposta de delimitação da calha do rio e da APP, realizada pela SUDEMA/PB, frente à legislação vigente.

\section{Marco legal sobre a questão das matas ciliares}

\section{1 Impactos ambientais e base geral da legislação aplicada aos} recursos hídricos

Impacto ambiental "é um conjunto de mudanças sociais e ecológicas causadas por perturbações no ambiente, como também a relação entre a natureza e sociedade que se transforma com o tempo e lugar" (COELHO, 2001, p. 24).

A Resolução $001 / 86$ do art. $1^{\circ}$ do Conselho Nacional do Meio Ambiente - CONAMA delibera impactos ambientais: 
matéria ou energia proveniente de atividades humanas que, indiretamente ou direta, afetam a saúde, segurança, bem estar da população, atividades sociais e econômicas, a biota, condições estéticas e sanitárias da ambiência e a qualidade dos recursos ambientais.

Tais impactos são causados pela modernização da sociedade, o que ocasionou diversas mudanças no Brasil e no mundo, aumentando, gradativamente, a necessidade de maior exploração dos recursos naturais, estimulando, com isso, a degradação ambiental. Entre as diversas agressões que ocorrem no ambiente urbano, estão aquelas referentes aos recursos hídricos, associadas à ocorrência de erosão, lançamento de efluentes industriais e de esgotos e despejo de lixo e entulho em áreas protegidas, como margens de rios e corpos d'água. 
No Brasil, diferentemente de muitos outros povos, de forma geral, os rios são desvalorizados, tornam-se ambientes degradados, marginalizados e negados pela sociedade. Assim, devido ao tratamento recebido, os cursos d'água acabam, muitas vezes, servindo de deposição de cadáveres, resíduos sólidos e locais de caminho de delinquentes (ALMEIDA, 2010).

Nessa mesma direção, Branco (2003) menciona:

\begin{abstract}
as grandes concentrações populacionais - principalmente nas grandes cidades - vêm criando problemas crescentes de poluição dos rios, solos e do ar, congestionamento do trânsito, problemas habitacionais, desmatamento de grandes áreas para a formação de novos pastos, campos de cultivo, represas para o abastecimento de água potável ou para a geração de energia elétrica (BRANCO, 2003, p.17).
\end{abstract}

Tais ações levam a população a abastecer-se de fontes que não sejam da rede de distribuição de água, correndo, então, riscos de contaminação de doenças, como o tifo, cólera, esquistossomose e doenças diarreicas que são transmitidos pela água poluída. No Brasil, a região Nordeste se destaca por ser aquela que tem a maior proporção de municípios com ocorrência de outras formas de abastecimento de água, que não provém de redes de tratamento (30,1\% dos municípios), segundo o Instituto Brasileiro de Geografia e Estatística - IBGE (2008).

Não é por falta de legislação que esse tipo de situação ocorre, pois, desde 1981, o legislador brasileiro já havia estabelecido a Política Nacional do Meio Ambiente - PNMA. Essa lei descreve, em seu art. $2^{\circ}$, os objetivos gerais: conservação, melhoria e o resgate da qualidade ambiental propícia à vida, objetivando garantir condições ao desenvolvimento socioeconômico, aos interesses da segurança nacional e ao resguardo da dignidade da vida humana (BRASIL, Lei $n^{\circ} 6.938$, de 31 de agosto de 1981). Nessa lei já havia referências à questão da proteção e racionalização dos recursos hídricos.

A constituição de 1988 também deixou claro, no seu art. 21, inciso XIX, que "compete à união, estabelecer o sistema nacional de gerenciamento de recursos hídricos e determinar critérios de outorga de direitos de seu uso. Deixando claro que não existem recursos hídricos de domínio dos Municípios" (BRASIL, Constituição de 1988, p.24). 
Conforme Pereira (2003), o Brasil vem tendo um notável avanço no campo da organização do sistema nacional dos recursos hídricos. Esse avanço só não é mais claro porque uma gestão eficaz dos recursos hídricos demanda a participação de toda sociedade, principalmente aqueles que mais utilizam a água, como agricultores e indústrias, envolvendo ainda mudanças culturais.

Para regulamentar o inciso XIX do Art. 21 da Constituição de 1988, foi criada a Lei Federal $n^{\circ}$ 9.433, de 8 de janeiro de 1997, mais conhecida como "Lei das águas", que instituiu a Política Nacional dos Recursos Hídricos e criou o Sistema Nacional de Gerenciamento dos Recursos Hídricos - SIGERH. Essa Lei, internacionalmente considerada uma das mais avançadas, traz conceitos novos, como a gestão participativa dos recursos hídricos e a atribuição do valor econômico à água inclusive para diluição de esgotos (PEREIRA, 2003). 


\subsection{Legislação Aplicada às Áreas de Preservação Permanente - APPs}

A Constituição federal menciona, em seu art. 225, que "todos têm direito a um meio ambiente ecologicamente equilibrado, bem de uso comum do povo e essencial à sadia qualidade de vida, impondo-se ao Poder Público e à coletividade o dever de defendê-lo e preservá-lo para a presente e futuras gerações" (BRASIL, Constituição de 1988, p.147).

Como regulamentador desse artigo da Constituição, foram implementadas diversas leis, dentre elas, o Código Florestal Brasileiro, que se apresenta atualmente na Lei $\mathrm{n}^{\circ} 12.651$, de 25 de maio de 2012, que dispõe sobre a proteção da vegetação nativa. A lei define os conceitos de APP, em seu art. $3^{\circ}$, como:

\footnotetext{
área protegida, coberta ou não por vegetação nativa, com a função ambiental de preservar os recursos hídricos, a paisagem, a estabilidade geológica e a biodiversidade, facilitar o fluxo gênico de fauna e flora, proteger o solo e assegurar o bem estar das populações humanas (BRASIL, Lei $n^{\circ} 12.651$, de 25 de maio de 2012).
}

O atual Código Florestal permite várias interpretações sobre APPs. Segundo Machado (2012), o conceito de APP, que antes era chamada de Floresta de Proteção Permanente, é agora denominada de Área de Proteção Permanente, sendo esta uma área coberta ou não por vegetação nativa, ou seja, pode ser uma área nua ou com qualquer tipo de vegetação. No entanto, a APP não é uma área qualquer e a sua proteção deve ser de forma permanente e não descontínua ou temporária. O termo permanente deve levar o comportamento individual do proprietário e de toda sociedade, no sentido de criar, manter e/ou recuperar a APP.

É obrigatório o proprietário da área, possuidor ou ocupante, recompor a área em caso de supressão indevida da vegetação. $O$ artigo $4^{\circ}$ menciona que são "APP's, em zonas rurais ou urbanas, I - as faixas marginais de qualquer curso d'água natural perene ou intermitente, excluídos os efêmeros, desde a borda da calha do leito regular, em largura mínima [...]", (BRASIL, Lei $n^{\circ} 12.651$, de 25 de maio de 2012).

Curso de água perene é o que tem continuidade ou que não sofre interrupção. Já curso de água intermitente é aquele que se manifesta a intervalos mais ou menos breves, ou que para e retorna, por intervalos. 
Curso de água efêmero é aquele que existe por pequeníssimo prazo, isto é, por um dia. Diante disso, ao exigir-se a existência da APP de proteção hídrica, não se pode confundir o curso de água intermitente com o curso de água efêmero (MACHADO, 2012).

A vegetação situada em APP deverá ser mantida, pois a intervenção ou supressão de vegetação nativa somente ocorrerá em caso de utilidade pública, de interesse social ou de baixo impacto ambiental. Atuando em desacordo com a legislação vigente do Código Florestal, o interventor sofrerá as medidas cabíveis, pois, no art. 38 da Lei $n^{\circ} 9.605 / 1998$, que dispõe sobre a lei dos crimes ambientais, discorre sobre a destruição e a utilização da floresta considerada de preservação permanente (MACHADO, 2012). 
Destruir ou danificar floresta considerada de preservação permanente, mesmo que em formação, ou utilizá-la com infringência das normas de proteção: Pena - detenção de 1 (um) a 3 (três) anos, ou multa, ou ambas as penas cumulativamente. Parágrafo Único. Se o crime for culposo, a pena será reduzida à metade (BRASIL, Lei $\mathrm{n}^{\circ}$ 9.605, de 12 de fevereiro de 1998, Art. 38).

$\mathrm{O}$ art. 38 da Lei 9.605 , de 1998, protege a floresta como um todo, isto é, o conjunto de árvores, independendo e sua extensão, abrangendo a noção de supressão da vegetação e de corte de árvores da floresta classificada como de Preservação Permanente. Para Machado (2012, p.38), "Floresta é o trecho de vegetação dominada por arvores de $3 \mathrm{~m}$ ou mais de altura, cujas copas se tocam ou quase se tocam".

$\mathrm{O}$ art. 39 da Lei $\mathrm{n}^{\circ}$ 9.605, de 1998, que dispõe sobre o corte de árvores em florestas de Preservação Permanente, menciona: "Cortar árvores em floresta considerada de preservação permanente sem permissão da autoridade competente: Pena- detenção, 1 (um) a 3 (três) anos, ou multa, ou ambas as penas cumulativamente" (BRASIL, Lei $\mathrm{n}^{\circ}$ 9.605, de 12 de fevereiro de 1998, p. 7). Nesse sentido, o crime consuma-se com o corte da árvore e com a ausência de licenciamento ambiental, como também a licença ambiental obtida irregularmente não elimina o crime. Não é preciso extrair a raiz da árvore, como também não precisa ser corte raso, bastando apenas que a ação danifique a árvore.

De acordo com o atual Código Florestal Brasileiro, artigo $4^{\circ}$, inciso I, alíneas de "a" a "i", essas APPs são dimensionadas nas margens em que devem ser implantadas, levando em conta a dimensão dos cursos de água natural perene e intermitente, excluídos os efêmeros, desde a borda da calha do leito regular e são previstas cinco medidas para APPs: $30 \mathrm{~m}$ para cursos d'água com até $10 \mathrm{~m}$ de largura; $50 \mathrm{~m}$ para cursos d'água com $10 \mathrm{~m}$ a $50 \mathrm{~m}$ de largura; $100 \mathrm{~m}$ para cursos de $50 \mathrm{~m}$ a $200 \mathrm{~m}$ de largura; $200 \mathrm{~m}$ para cursos de $200 \mathrm{~m}$ a $600 \mathrm{~m}$, e $500 \mathrm{~m}$ para cursos de largura superior a 600m (BRASIL, Lei $n^{\circ} 12.651$, de 25 de maio de 2012).

No Estado da Paraíba, o Código Florestal dispõe sobre a Política Florestal do Estado. Em seu art. $1^{\circ}$, menciona que "as Florestas nativas e demais formas de vegetação natural existente no território estadual, reconhecidas de utilidade das serras que revestem, são consideradas 
bens de interesse comum a todos os habitantes do Estado [...]" (PARAÍBA, Lei $n^{\circ}$ 6.002, de 29 de dezembro de 1994).

Dentre os objetivos específicos da política florestal do Estado, no que diz respeito à APP, ela se refere a promover a recuperação de áreas degradadas, especialmente nas áreas de preservação permanente, reserva legal, entorno das unidades de conservação, bem como proteger áreas ameaçadas de degradação, conforme está na Lei $6.002 / 94$, art. $3^{\circ}$ inc. IX. O capítulo segundo da referida lei, que trata da exploração e reposição florestal, descreve que "toda exploração florestal no Estado dependerá de prévia autorização do órgão competente" (PARAíBA, Lei n 6.002, de 29 de dezembro de 1994).

Estão descritos em seus artigos 18 e 19 que, em projetos de manejo de bacias hidrográficas, o poder público estadual deverá priorizar a proteção de cobertura vegetal dos mananciais de abastecimento públicos, como também é proibido o uso de fogo e queimadas nas florestas e demais formas de vegetação florestal (PARAÍBA, Lei $n^{\circ}$ 6.002, de 29 de dezembro de 1994).

No Município de Patos, existe a Lei $N^{\circ} 3.503$, de 06 de outubro de 2006, que define o Plano Diretor de Desenvolvimento Integrado do Município e dá outras providências. Segundo o seu art. $1^{\circ}$, o Plano Diretor é uma ferramenta básica e estratégica da política de desenvolvimento do Município, tendo como seu principal objetivo conduzir a ação do poder público juntamente com a iniciativa privada na construção dos espaços, no meio rural e urbano, tendo em vista propiciar melhores condições de vida para a população (PATOS, Lei $\mathrm{n}^{\circ}$ 3.503, de 06 de outubro de 2006).

Os objetivos básicos referentes às leis específicas e complementares a esse plano estão descritos em seu art. $4^{\circ}$, inc. I, II e III:

\footnotetext{
I - Proteger, preservar e restaurar o Meio Ambiente; II - Prevenir ocorrências de distorções do crescimento urbano; III- Evitar e prevenir as incompatibilidades de uso do solo; V - Controlar as densidades, populacionais no território urbano (PATOS, Lei $n^{\circ}$ 3.503, de 06 de outubro de 2006).
}

Para garantir esses objetivos de acordo com o $\S 1^{\circ}$, "foram criadas as leis específicas e complementares que se configuram como instrumentos de planejamento são elas: Código de Uso e Ocupação do 
Solo Urbano e Rural; Código de Urbanismo; Código de Edificações; Código de Posturas e Código do Meio Ambiente" (PATOS, Lei $n^{\circ} 3.503$, de 06 de outubro de 2006). Em seu art. 18, nos incisos de I a XII, são apresentadas as diretrizes e projetos que contemplam a Política Habitacional:

I - Criação de uma política de moradia na cidade; II - Definir uma política de saneamento básico; III - Concretizar a reurbanização de áreas ocupadas por favelas; IV - Concretizar a regularização fundiária das áreas de ocupação irregular; V Reassentar as populações residentes em áreas de risco, insalubridade e preservação ambiental; VI - Implantar lotes urbanizados e construção de Conjuntos Habitacionais para população comprovadamente carente, conforme o Artigo 15 inciso VII dessa Lei; VII - Implantar processos construtivos (mutirões); VIII - Criar formas de financiamentos; IX Reconstruir moradias de população que se enquadrem na descrição do Artigo 15, inciso VII dessa Lei; X - Distribuir cesta básica de materiais de construção segundo critérios implícitos Artigo 15, inciso VII dessa lei; XI - Formação de estoques de áreas para fins habitacionais e XII - Cumprir a legislação urbanística (PATOS, Lei $n^{\circ} 3.503$, de 06 de outubro de 2006).

$\mathrm{Na}$ cidade de Patos, há amparo da lei para evitar ocupações de APPs, porém existem ocupações tanto de classes de menor renda como de maior renda. São vários os programas e projetos assegurados pelo plano diretor em relação às áreas de preservação permanente, como no art. 18, que caracteriza que a política habitacional contemplará diretrizes e projetos como: " $\mathrm{V}$ - Reassentar as populações residentes em áreas de risco, insalubridade e preservação ambiental" (PATOS, Lei $\mathrm{n}^{\circ}$ 3.503, de 06 de outubro de 2006). 
O Plano Diretor de 2006 dispõe sobre política ambiental e tem como objetivos básicos, no art. 4 :

\begin{abstract}
I- Preservar, melhorar e recuperar o meio ambiente; II Integrar ações ligadas à defesa do Meio Ambiente; III estabelecer critérios e padrões de qualidade ambiental; IVImpor ao poluidor e ao agressor do meio ambiente a obrigação de recuperar e indenizar os danos causados ao meio ambiente; $\mathrm{V}$ - Fomentar a consciência pública sobre a necessidade de preservar e manter a qualidade ambiental e o equilíbrio ecológico; VI - Desenvolver atividades educativas junto à comunidade, com o intuito de resgatar a qualidade de vida e do meio ambiente; VII - Compatibilizar a política ambiental com políticas setoriais, principalmente da de uso e ocupação do solo; VIII - implantar a coleta seletiva do lixo urbano e IX - Dar destino adequando ao lixo urbano e rural (PATOS, Lei $n^{\circ} 3.503$, de 06 de outubro de 2006).
\end{abstract}

O Plano Diretor de 2006 deixa claro, a respeito das APPs, em seu art. 30, inciso XVIII, que é objetivo da lei "impedir a ocupação das margens dos rios, barragens e açudes por habitações irregulares com monitoramento e vigilância, com comunicações, com as associações de moradores de bairros e das áreas ribeirinhas" (PATOS, Lei $n^{\circ} 3.503$, de 06 de outubro de 2006).

$\mathrm{Na}$ cidade de Patos, existe também o Conselho Municipal do Meio Ambiente - CMMA, que define APPs como: "porções do território municipal, de domínio público ou privado, destinadas à preservação de suas características ambientais e ecossistemológicas relevantes, assim definidas em lei" (PATOS, Lei $n^{\circ} 3.486$, de 09 de maio de 2006).

Dentre as atribuições do CMMA, citadas em seu artigo 12, parágrafo III, alínea "f", está "A definição de áreas de proteção ambiental, reservas ecológicas, estações ecológicas de especial interesse turístico, preservação permanente, relevante interesse ecológico e outras a serem tombadas pelo Poder Público" (PATOS, Lei n³.486, de 09 de maio de 2006).

Ainda no CMMA do Município de Patos, no seu artigo 12, incisos I e II, definem-se Zonas de Preservação Permanente como "florestas, matas ciliares e faixas de proteção das águas superficiais; mananciais e nascentes". (PATOS, Lei n $^{\circ} 3.486$, de 09 de maio de 2006). 
As APPs podem ser alteradas ou suprimidas, quando se troarem de obras de relevante interesse social. Nesse caso, tanto o Código Florestal como a legislação local permitem a destruição das APPs, mediante a autorização dos respectivos órgãos ambientais.

\subsection{Conflitos na Delimitação das Áreas de Preservação Permanente Urbanas}

A ocupação urbana no território brasileiro foi bastante influenciada pela forma de colonização dos povos ibéricos, em que a ocupação de topos de morro, áreas ciliares, várzeas e margens de rios e lagoas eram comuns àquela época (MIRANDA, 2008). Em sequencia, a ocupação urbana se dava com a construção de avenidas e ruas às margens dos corpos hídricos. Isso, associado ao desmatamento de encostas, causou a irregularidade do fluxo das águas em áreas urbanas e todas as suas consequências, conforme assevera Machado,

a ocupação do solo sem atendimento a padrões de sustentabilidade ambiental, específicos para a área, e a adoção de padrões urbanísticos gerais, que não promovem a identificação das particularidades de cada uma das áreas das cidades, associado ao êxodo rural e as pressões habitacionais, leva, cada vez mais, nossas cidades a situações insustentáveis, deixando a população, a cada ano, sujeita às intempéries, sem possibilidade de previsão desses efeitos, que se somam em progressão de danos, a cada nova estação de chuvas (MACHADO, 2012, p.1).

Esses fatores impulsionam a ocupação de áreas impróprias, como margens de rios ou topos de morros, tanto por moradores de baixa renda ou condomínios de alto padrão, ou até mesmo pela infraestrutura pública, como abertura de avenidas marginais.

Existem vários conflitos entre as normas ambientais $e$ as de disciplinas urbanísticas e parcelamento do solo, pois há imprecisão na definição e função da área legal das APPs, o que dá margem a interpretações variadas, conduzindo ao descumprimento da norma em áreas urbanas, como também o aumento da divergência das leis acerca da competência legislativa dos órgãos federativos (DAMIS, 2006). Para Azevedo e Oliveira $(2014$, p. 73$)$, o termo "preservação permanente" 
apareceu no âmbito da Lei $\mathrm{n}^{\circ} 4771$ de 1965, que foi o segundo Código Florestal Brasileiro.

Decorridos justos 50 anos, desde a edição da Lei Federal $n^{\circ}$ 4.771/1965, que foi revogada e substituída pelo atual Código Florestal, verifica-se que, na maioria das cidades brasileiras, sejam pequenas ou grandes, não se reconheceu a existência ou importância das APPs, mesmo com os benefícios que estas áreas proporcionam para a qualidade de vida e equilíbrio ecológico.

Para Sepe et al. (2014), uma sequência de alterações do Código Florestal, que se passou entre a edição da Constituição federal de 1988 e a instituição da Lei Federal 7.803/1989, que faz referência sobre a delimitação das APPs, em especial a sua aplicabilidade em área urbana, tornando obrigatória a matrícula no imóvel rural juntamente com a reserva legal, só foi possível devido à pressão ocasionada por problemas ambientais relacionados a enchentes e ao desmatamento no país.

$O$ atual Código Florestal (Lei $n^{\circ} 12.651 / 2012$ ), antes de entrar em vigor, passou por um amplo e conturbado processo de discussão na Câmara dos Deputados e no Senado Federal. De acordo com Sepe et al., (2014), não houve tempo para discussão sobre as regras de proteção desses espaços em áreas urbanas, no entanto, cidades se desenvolveram e se desenvolvem legalmente e ilegalmente sobre as porções do território que o Código Florestal visa proteger, pois atualmente existe, em boa parte das cidades brasileiras, ocupação consolidada praticamente impossível de se reverter.

Os principais impactos gerados pelo atual Código Florestal em APPs urbanas decorrem nas hipóteses de utilidade pública e de interesse social. Como previsão do art. 8 do Código Florestal, "a intervenção ou a supressão de vegetação nativa em Área de Preservação Permanente somente ocorrerá nas hipóteses de utilidade pública, de interesse social ou de baixo impacto ambiental [...]" (BRASIL, Lei $n^{\circ} 12.651$, de 25 de maio de 2012).

Como também, em seu $\S 3^{\circ}$, artigo $8^{\circ}$, expõe que "é dispensada a autorização do órgão ambiental competente para execução de atividades de segurança nacional e obras de interesse de defesa civil destinadas à prevenção de acidente em áreas urbanas" (BRASIL, Lei $\mathrm{n}^{\circ}$ 12.651 , de 25 de maio de 2012). 
Para a supressão de árvores ou formações arbóreas, ou mesmo para ocupar essas áreas, é preciso que o legislativo local declare em lei a ser votada que aquela área é de interesse social. Para Damis (2006), esses parágrafos comprovam que o grau de impacto está diretamente proporcional ao rigor no tratamento das APPs, pois, quanto maior a flexibilidade no tratamento dos recursos naturais situados em áreas urbanas, maiores os impactos presentes nessas áreas, pois trata-se de áreas com intensa pressão populacional, destinadas a atender aos pedidos da comunidade.

É preciso compreender que o principal problema na aplicação do Novo Código Florestal é que a lei não foi pensada para ser aplicada em áreas urbanas, assim como a lei anterior (Lei Federal $n^{\circ} 4.775 / 1965$ ), pois, mesmo com o avanço da redação do art. $4^{\circ}$, que não deixa dúvidas quanto à existência de áreas de preservação permanente em espaço urbano, também se torna muito genérica, não sendo permitida a adequação para as diferentes situações nas cidades brasileiras, sendo o caso de São Paulo o mais representativo (SEPE et al., 2014, SANTOS e SCAGLUISI, 2011).

Foram realizadas várias alterações sobre as APPs em áreas urbanas, pois, inicialmente, o texto era dado pelo atual Código Florestal no art. $4^{\circ}$, parágrafos $4^{\circ}$ e $8^{\circ}$.

$\S 7^{\circ}$. Em áreas urbanas, as faixas marginais de qualquer curso d'água natural que delimitem as áreas da faixa de passagem de inundação terão sua largura determinada pelos respectivos Planos Diretores e Leis de Uso do Solo, ouvidos os Conselhos Estaduais e Municipais de Meio Ambiente. $\S 8^{\circ}$. No caso de áreas urbanas e regiões metropolitanas, observar-se-á o disposto nos respectivos Planos Diretores e Leis Municipais de Uso do Solo. (BRASIL, Lei $n^{\circ} 12.651$, de 25 de maio de 2012).

Observa-se que o intuito do Congresso Nacional era confiar aos municípios a possibilidade, por meio de seus Planos Diretores e Leis Municipais de Uso do Solo, de estabelecerem faixas de APPs diferenciadas, podendo estas ser maiores ou menores que as metragens previstas no atual Código Florestal para zonas rurais. Ocorre que a presidente da República vetou tais dispositivos na Mensagem de Veto $\mathrm{n}^{\circ}$ $212 / 2012$, pronunciando que tais parágrafos seriam um retrocesso à luz da legislação em vigor, ao dispensar a necessidade de observância 
dos critérios naturais e proteção da infraestrutura (AZEVEDO e OLIVEIRA, 2014).

Segundo Maciel (2010), existia conflito entre a Lei $n^{\circ} 6.766$, de 1979 (que dispõe sobre parcelamento do solo urbano) e o antigo Código Florestal, pois, em seu art. $4^{\circ}$, inciso III, na redação dada pela Lei $n^{\circ} 10.932$, de 2004 - altera o art. 4ㅇ da Lei no 6.766, de 19 de dezembro de 1979 -, (dispõe sobre o parcelamento do solo urbano e dá outras providências). Menciona o artigo a obrigação, dentre outros requisitos, de reservar uma faixa não edificável de $15 \mathrm{~m}$ de cada lado ao longo das águas correntes e dormentes e das faixas de domínio público das rodovias, salvo maiores exigências da legislação específica. Sabe-se que os limites de APPs estabelecidos pelo antigo Código Florestal, continuando no atual Código, na mesma situação, ao redor de lagos e represas seriam muito superiores a $15 \mathrm{~m}$ da Lei de Parcelamento do Solo.

É necessária a edição de um novo regramento legal específico para áreas urbanas, a qual poderia propiciar uma melhor eficiência de sua aplicação, pois os critérios para elaboração de um novo documento não são simples de serem estabelecidos e devem se basear em diagnósticos de bacias hidrográficas, debatidos por profissionais de diversas formações e serem estabelecidos prioritariamente por um colegiado com participação popular (SANTOS e SCAGLUISI, 2011).

Segundo o Instituto de Pesquisas Ambientais da Amazônia - IPAM (2014), as regras vigentes no antigo Código Florestal para as APPs garantiam a integridade mínima dessas áreas sensíveis. No entanto, no atual código, essa certeza não existe, pois a revisão do mesmo foi pautada por razões políticas e econômicas e não por um debate técnico e científico sobre padrões mínimos de conservação.

Várias mudanças foram realizadas no atual Código Florestal, relacionadas aos cursos d'água, como a nova redação dada ao art. 4, I : " I- as faixas marginais de qualquer curso d'água natural perene e intermitente, excluídos os efêmeros, desde a borda da calha do leito regular, em largura mínima de [...]"(BRASIL Lei $\mathrm{n}^{\circ} 12.651$, de 25 de maio de 2012). Ou seja, serão contabilizadas da borda da calha do leito regular e não do seu nível mais alto, reduzindo, assim, a sua proteção. Os cursos de água natural que terão faixas marginais florestadas são 
aqueles que forem de natureza "perene e intermitente, excluídos os efêmeros".

Outra questão é a definição de nascentes e olhos d'água, considerando APPs somente as áreas no entorno das nascentes e dos olhos d'água perenes no raio mínimo de $50 \mathrm{~m}$. Saber os limites da calha de um rio não é simples. É preciso acompanhar todo o percurso do rio, uma vez que no mesmo existe variação na largura da calha, para, assim, determinar a APP.

No Município de Patos, não é permitido o parcelamento do solo como descrito em seu artigo 130: "I - terrenos alagadiços e sujeitos a inundação, antes de tomadas às providências para assegurar o escoamento das águas" (PATOS, Lei n 3.486, de 09 de maio de 2006).

\section{Caracterização da área de estudo e procedimentos metodológicos}

\section{1 Local de Estudo}

O presente estudo foi desenvolvido na cidade de Patos-PB, mais precisamente na área urbana em que parte do Rio Espinharas e dos seus afluentes formadores defluem, cruzando a cidade. A sede municipal se localiza nas coordenadas geográficas ( $7^{\circ} 01$ '23.94'’S e $37^{\circ} 16^{\prime} 44.26^{\prime \prime} \mathrm{W}$ ), parte centro-oeste do Estado da Paraíba, com uma altitude de $245 \mathrm{~m}$ com relação ao nível do mar e área de $506,5 \mathrm{Km}^{2}$. A população residente no município é de 105.531 habitantes (IBGE, 2014). 
Em conformidade com a região na qual se encontra a cidade, o clima é semiárido (Bsh), de acordo com a classificação de KoopenGeiger, quente e seco, com temperatura média anual de $25,5^{\circ} \mathrm{C}$ e com precipitação média de $728 \mathrm{~mm}$ (KOPPEN, 1948).

Com relação aos solos encontrados na cidade, são encontrados três tipos de solos: os LUVISSOLOS Crômicos Órticos de ordem zonal, que é uma denominação dada aos antigos bruno-não cálcicos, seguidos do NEOSSOLOS Litólico Eutróficos e os NEOSSOLOS flúvicos antigos ALUVIAIS (SIBCS, 2013).

A sua localização privilegiada ao centro geográfico da Paraíba e a proximidade com os estados do Pernambuco e Rio Grande do Norte asseguraram uma centralidade para onde convergem vários municípios, servindo-os como de centro de comercialização e prestação de serviços, com ênfase na saúde e educação (AQUINO, 2012).

O Rio Espinharas é o mais importante da região de Patos-PB, formado pelos Rios da Cruz e Farinha. Esses rios nascem nas encostas da Serra do Teixeira-PB e se juntam no perímetro urbano da cidade de Patos-PB, formando o Rio Espinharas, que corre em direção ao norte, penetrando no Estado do Rio Grande do Norte (SANTOS, 2013). Salienta-se que, para efeito deste trabalho, quando se refere ao trecho urbano do Rio Espinharas, subentende-se que faz parte do estudo o trecho urbano dos Rios Farinha e Cruz.

\subsection{Materiais e Softwares Utilizados}

Para a execução dos trabalhos de campo, os técnicos da Sudema utilizaram: estacas de madeira; pranchetas; lápis; câmera digital; facão; GPS Trimble Juno 3 (demarcar coordenadas geográficas).

A análise dos dados foi realizada em planilha eletrônica (Microsoft Excel 2010) e, para a sobreposição de pontos de delimitação de áreas, usaram Imagem Google Earth 2012.

\subsection{Delimitação e impactos ambientais do Rio Espinharas}

A demarcação das APPs aqui apresentada é fruto de um trabalho realizado pela SUDEMA - Núcleo de Patos, e foi realizado no período de janeiro a abril de 2014. 
Antes da delimitação, foi realizada a preparação de todo material, como mapas de localização realizados no Google Earth para o planejamento da ida ao campo. Para este trabalho, obteve-se o auxílio de dois técnicos que vieram da SUDEMA - Núcleo de João Pessoa-PB, um técnico geógrafo especializado em Sistema de Informações Geográficos - SIG e um engenheiro ambiental especializado em topografia. Foi realizada a confecção de estacas para colocar como referência em caso de necessidade de retorno ao campo.

Para elaboração do mapa, foi criado um mosaico de imagens gratuitas de satélites do Google Earth para uma melhor delimitação e visualização das APPs. Depois, foi realizado um levantamento in loco, com o auxílio de GPS do tipo Trimble Juno 3 Série. Esse levantamento serviu para o georreferenciamento de pontos de controle para a delimitação das APPs e de pontos de esgotos, e também para o levantamento dos impactos a que está submetido o Rio Espinharas. Foram coletados e marcados 173 pontos na calha do leito regular do rio para confecção do mapa, por todo o percurso do Rio Espinharas, marcando-se, a cada curva, o máximo de pontos possíveis para não ficar nenhuma parte do rio de fora do mapa. Os percursos foram $2 \mathrm{~km}$ do Rio Farinha, $3 \mathrm{~km}$ do Rio da Cruz e $4 \mathrm{~km}$ do Rio Espinharas. Somando-se as duas margens, deu-se um percurso de $17 \mathrm{~km}$. Contudo, devido aos obstáculos encontrados, como cercas e muros, dificultando ainda mais o processo de demarcação, verificou-se um total de $20 \mathrm{~km}$ de caminhadas por todo o percurso do rio da área urbana de Patos-PB.

Para estruturar o banco de dados georreferenciados que serviu de base para a delimitação das APPs, utilizou-se a Carta Topográfica Digital do Município de Patos, produzida pela Superintendência do Desenvolvimento do Nordeste - SUDENE, na escala 1:25.000, que possui os seguintes temas: limite do município, hidrografia, sistema viário, curvas de nível e pontos cotados. As larguras das APPs foram inseridas na tabela de dados do arquivo tipo shapefile de cada tema, associandoas conforme as feições geométricas que representam os cursos d'água, de acordo com o Novo Código Florestal, que é a Lei $n^{\circ} 12.651$, de 25 de maio de 2012.

As definições para delimitação das APPs estão descritas no Art. $2^{\circ}$. Leva-se em conta a dimensão dos cursos de água natural perene e intermitente, excluídos os efêmeros, desde a borda da calha do leito 
regular. São previstas cinco medidas para APPs: $30 \mathrm{~m}$ para cursos d'água com menos de $10 \mathrm{~m}$ de largura; $50 \mathrm{~m}$ para cursos d'água de $10 \mathrm{~m}$ a $50 \mathrm{~m}$ de largura; $100 \mathrm{~m}$ para cursos de $50 \mathrm{~m}$ a $200 \mathrm{~m}$ de largura; $200 \mathrm{~m}$ para cursos de $200 \mathrm{~m}$ a $600 \mathrm{~m}$, e $500 \mathrm{~m}$ para cursos de largura superior a 600m (art. 4, I, "a" a "i") (BRASIL, Lei $\mathrm{n}^{\circ} 12.651$, de 25 de maio de 12, art. $2^{\circ}$ ). Para isso, utilizou-se o SIG ArCGIS 9.3 para realizar as tarefas de geoprocessamento.

No tema hidrografia, os rios são representados por linhas simples, então não é possível determinar quais são as larguras dos mesmos. Dessa forma, as larguras foram medidas com o auxílio do programa Google Earth, por meio das imagens de satélite disponibilizadas, e, para cada rio, foi inserida, no banco de dados, a largura de sua APP. Foi atribuído, no banco de dados, o valor de $50 \mathrm{~m}$ de largura de APP.

As APPs da hidrografia foram desenhadas no mapa utilizando-se a ferramenta delimitação de área equidistante (buffer), que construiu um polígono ao redor dos elementos geométricos representantes dos corpos d'água com a largura que havia sido especificada no banco de dados. Nas APPs mapeadas, foi realizada a identificação do uso e ocupação da terra por meio da interpretação visual de imagem do programa Google Earth referente à passagem em 05/03/2013, seguida da realização de um trabalho de campo onde foram visitadas as APPs e observadas as formas de uso e ocupação presentes no local como forma de averiguação do que havia sido interpretado por meio da imagem de satélite, além do registro fotográfico das áreas. 


\section{Impactos ambientais e análise crítica da delimitação da área de mata ciliar do Rio Espinharas, Patos-PB}

\section{I Impactos ambientais a que está submetido o Rio Espinharas}

Os impactos ambientais encontrados no Rio Espinharas, no perímetro urbano da cidade de Patos-PB, são vários. Dentre eles, está a extinção da mata ciliar, que é considerada um dos principais problemas encontrados nos rios urbanos. No presente trabalho, durante todas as atividades e percurso realizado, constatou-se o que já havia sido mencionado por Aquino (2011,p. 35 ), "esse tipo de vegetação foi retirada ou substituída em quase $80 \%$ de sua área, dentro do município de Patos".

O que acontece no Rio Espinharas corrobora com o que foi mencionado por Coelho (2001). Para esse autor, Impacto Ambiental é um processo de mudanças sociais e ecológicas ocasionado por perturbações no ambiente, tendo relação entre sociedade e natureza, que se transformam de maneira dinâmica. Esses impactos vêm aumentando nas últimas décadas e se tornando cada vez mais visíveis devido à presença de resíduos sólidos e líquidos, intenso desmatamento da mata ciliar, invasão, ocupação desordenada nas áreas de preservação permanente e a quantidade de sedimentos na água. Isso é o que está acontecendo na cidade de Patos, na relação entre a sociedade local e o principal rio que corta a cidade.

Outro impacto que foi bastante encontrado no Rio Espinharas é o assoreamento, que é um processo resultante da ausência da mata ciliar e do processo de antropização no entorno do rio, conforme Medeiros (2011). A tendência é que o rio se torne cada vez mais raso, intensificando cada vez mais a ocorrência de inundações das áreas próximas, causando vários prejuízos à população "patoense".

Pode-se constatar a presença marcante de resíduos sólidos nas margens e no leito do Rio Espinharas. Aquino (2011) menciona que esse é um problema de falta de educação ambiental, pois já foram realizadas coletas desse material das margens dos rios. Segundo o autor, o problema é que, após a limpeza, não ocorre uma conscientização ambiental por parte da população e principalmente a ribeirinha. Conforme a AESA (2009), os resíduos sólidos não têm coleta nem 
destino adequado na maioria dos municípios paraibanos, e o acúmulo destes resíduos se dá terrenos em baldios, assim como seu despejo em riachos e córregos, como os que podem ser registrados em Patos.

O hábito das pessoas jogarem lixo pode ser explicado por Mucelin e Bellini (2006). De acordo esses autores, a cultura, costumes e hábitos de um povo ou comunidade caracterizam a forma e o uso do ambiente, como também a produção de lixo e como esses produtos são tratados e descartados. Esses maus hábitos geram montanhas de lixo em ambientes inadequados, como terrenos baldios, rios, lagos calçadas ou açudes.

Foram identificados e georreferenciados 29 pontos de lançamento de esgoto com volumes significativos, ou seja, aqueles facilmente percebidos, provenientes de canais naturais e/ou rede pluvial (figura 1). Esse é o reflexo da falta de saneamento da cidade em que mais de $90 \%$ do esgoto se destina ao rio, ocasionando a poluição e degradação do mesmo. Salienta-se ainda que, além dessa poluição facilmente identificada, há aquela difusa, proveniente de lançamentos de esgoto de pequena escala pelos residentes, o que indica que 0 problema é ainda maior.

Figura 1. Pontos de esgoto georreferenciados e sobrepostos em imagem Google Earth às margens dos Rios: Espinharas, Cruz e Farinha, no perímetro urbano de Patos-PB. 2014

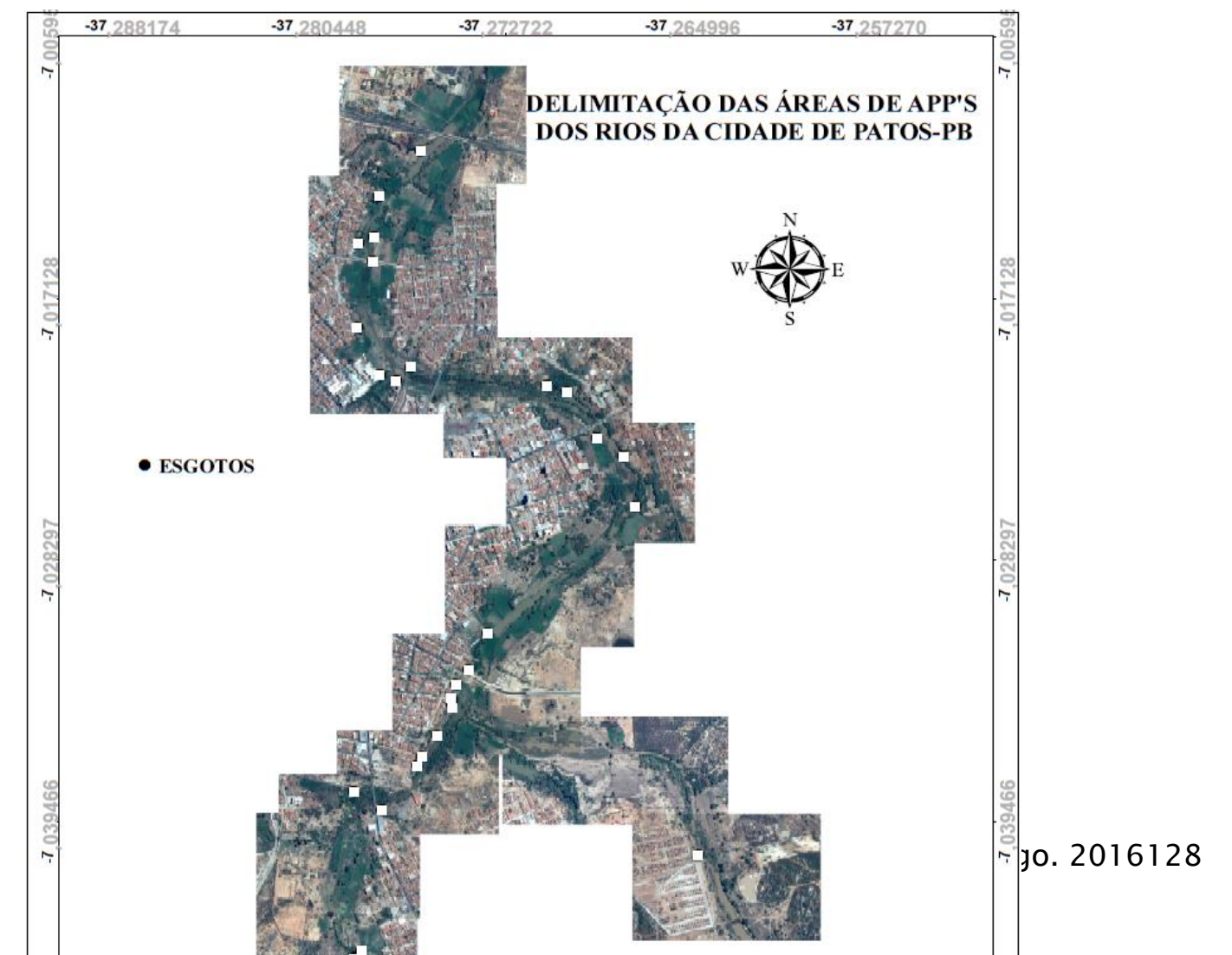


João Batista Alves

Fonte: SUDEMA (2014).

Redes (St. Cruz Sul, Online), v. 21, n² 2, p. 107 - 130, maio/ago. 2016129 
Santos e Scagluisi (2011) já citavam que o Rio Espinharas no perímetro urbano recebe esgotos domésticos, industriais e hospitalares, sem nenhum tipo de tratamento, devido à cidade não dispor de estação de tratamento de esgoto. Esse fato está acabando com as chances de revitalização do rio e apagando da memória das pessoas o local que, para muitos, serviu de fonte de lazer e alimento e que matou a sede e a fome da população em determinado tempo (CATARINA, 2003).

Essa realidade não é só da cidade de Patos. Segundo o IBGE (2008), apenas 55,2\% das cidades brasileiras dispunham do serviço de esgotamento sanitário por rede coletora, que é considerado um sistema apropriado, não diferente do ano de 2000 , que constava de $52,3 \%$, mostrando uma pequena evolução em oito anos de gestão. A cidade de Patos encontra-se na situação dos outros municípios que não tratam dos seus esgotos.

Para Tundisi (2003), as atividades que causam impactos aos rios são: urbanização e despejos de esgotos sem tratamento; construção de estradas; mineração, hidrovias, construção de represas, atividades industriais, introdução de espécies exóticas, disposição de resíduos sólidos e desmatamento nas bacias hidrográficas.

A presença de resíduos, assim como o despejo de esgoto doméstico e industrial, permitiu verificar a eutrofização do manancial, tendo em vista o crescimento excessivo de algas e plantas aquáticas aparecendo na superfície da água. Conforme Netto (2010), a eutrofização pode levar a várias alterações na água como, por exemplo: no sabor; no odor; na turbidez; na cor da água; além da redução do oxigênio dissolvido, que provoca a morte peixes e outras espécies aquáticas.

O que foi constado em Patos-PB corrobora com Medeiros (2011), que menciona que os esgotos domésticos são os principais focos de poluição orgânica nas águas nordestinas, devido à falta de estações de tratamento de esgotos, pois, na Paraíba, só existem 16 estações de tratamento de esgotos domésticos, mas que precisam ser modernizadas.

4.2 Proposta de delimitação da calha do rio e das Áreas de Preservação Permanente - APPs 
A primeira questão a ser discutida é o mérito da proposta. Do ponto de vista científico, há uma fragilidade na delimitação da calha do rio no que concerne alguns requisitos técnicos, conforme aqueles recomendados, por exemplo, por Christofoletti (1981), Suguio (2003), Pinheiro (2005), entre outros, pois não se fez um estudo pormenorizado do perfil da calha do rio. Na mesma seara, o georreferenciamento de pontos coletados, feito a partir de GPS com baixo grau de precisão que se requer neste tipo de trabalho.

Nesse sentido, Soares-Filho (2013) menciona que devido à ausência de informações sobre a largura dos rios, há um enorme grau de incertezas quanto ao mapeamento brasileiro de APPs. Ribeiro et al. (2005) menciona que apesar dos avanços na conscientização ecológica e legislação no Brasil, a deficiência estrutural do Estado não avança na aplicabilidade, pois há incapacidade de fazer cumprir a legislação e há, também, o despreparo técnico e ineficiência na infraestrutura.

A situação da proposta de delimitação de APP, neste caso em estudo, enquadra-se na vertente do pensamento desses autores mencionados. No entanto, como proposta que suscita tanto ao órgão ambiental, bem como à sociedade local, uma discussão a respeito do problema ambiental dos referidos rios e a delimitação das suas respectivas APPs, é perfeitamente válido.

A discussão que se abre em seguida é se as legislações vigentes nos três entes federados, objeto deste estudo, dão suporte a tal proposta de delimitação ou há fragilidade ou mesmo "gaps" que viabilizem ou não sua execução. Tem-se a convicção que a discussão aqui empreendida irá contribuir para esse problema que atinge a maioria dos municípios brasileiros.

O mapa na figura 2 mostra a marcação dos pontos coletados durante o percurso do Rio Espinharas, os trechos dos dois afluentes que o formam, na área urbana do Município de Patos-PB, sendo percorrida uma distância de aproximadamente $20 \mathrm{~km}$ de caminhada, devido às barreiras artificiais e/ou naturais (cercas, muros, canais naturais ou artificiais), conforme já mencionado. As interferências artificiais foram feitas por residentes que acabam fazendo uso ou apropriações indevidas das margens dos rios para atividades diversas, sendo a principal o plantio de gramíneas para alimentação de animais, no próprio local ou proximidades. 
Na figura 3, apresenta-se a proposta de delimitação da calha dos rios, visto que, para o rio principal (Espinharas), a calha apresenta irregularidades na sua largura por severas modificações devido à antropização, sendo o assoreamento a principal causa. As larguras variaram entre $10 \mathrm{~m}$ e $50 \mathrm{~m}$. Dessa forma, a proposta da SUDEMA é delimitar a APP em 50m, ou seja, adotou-se a largura de calha maior. 
Figura 2. Pontos georreferenciados e sobrepostos em imagem Google Earth, usados pela Sudema para proposta de delimitação da calhado dos rios Espinharas, Cruz e Farinha, no perímetro urbano de Patos-PB. 2014

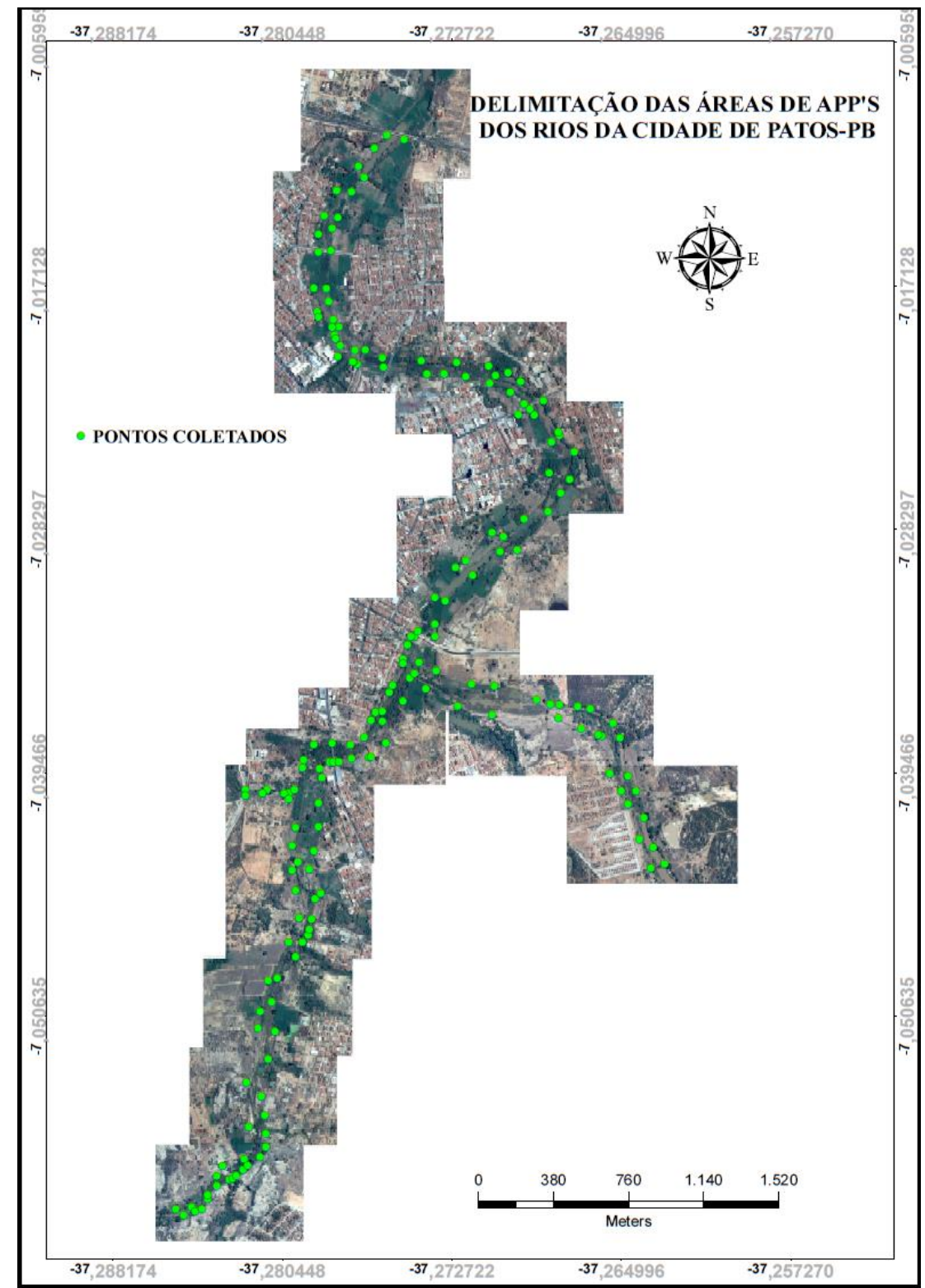

Fonte: SUDEMA (2014). 
Somado ao uso agropecuário, embora não seja perceptível no mapa devido à escala, existem ainda, no local, casas, ruas, avenidas, construções, empreendimentos públicos e particulares dentro das APPs do Rio Espinharas, demostrando que há ocupações irregulares em quase o todo rio, no perímetro urbano da cidade de Patos-PB. Machado (2012) descreve que: 
Figura 3. Delimitação da calha e das APP's dos Rios Espinharas, Cruz e Farinha, feita pela SUDEMA, sobreposto em imagem no Google Earth, no perímetro urbano de Patos-PB. 2014

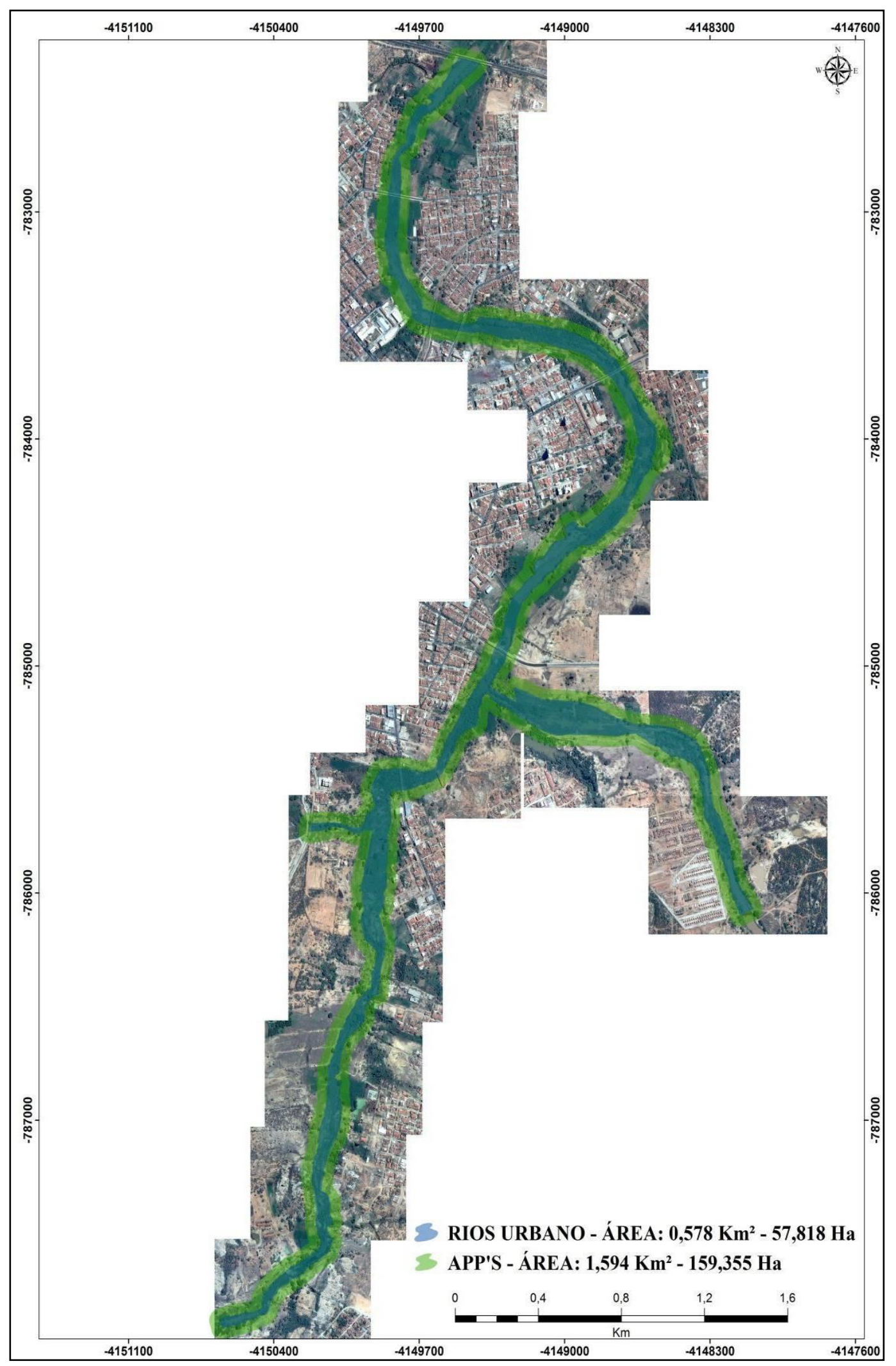

Redes (St. Cruz Sul, Online), v. 21, n² 2, p. $107-130$, maio/ago. 2016135 
Fonte: SUDEMA (2014).

\begin{abstract}
A ocupação do solo sem atendimento a padrões de sustentabilidade ambiental, específicos para a área, e a adoção de padrões urbanísticos gerais, que não promovem a identificação das particularidades de cada uma das áreas das cidades, associado ao êxodo rural e as pressões habitacionais, leva, cada vez mais, nossas cidades a situações insustentáveis, deixando a população, a cada ano, sujeita às intempéries, sem possibilidade de previsão desses efeitos, que se somam em progressão de danos, a cada nova estação de chuvas. (MACHADO, 2012, p.1)
\end{abstract}

É preciso compreender que o principal problema na aplicação do atual Código Florestal é que a lei não foi pensada para ser aplicada em áreas urbanas, assim como a lei anterior (Lei Federal $n^{\circ} 4.775 / 1965$ ), pois, mesmo com o avanço da redação do art. $4^{\circ}$, que não deixava mais claro quanto à existência de APPs em espaço urbano, também se tornava muito genérico, pois não permitia a adequação para as diferentes situações nas cidades brasileiras, sendo o caso de São Paulo o mais representativo (SEPE et al., 2014, SANTOS e SCAGLUISI, 2011 ).

Por outro lado, conforme pode ser visto no referencial teórico, as legislações estadual e municipal apresentam artigos que dão suporte legal à delimitação das APPs em ambiente urbano. Se o regime das APPs, mesmo nas áreas urbanas, está respaldado nas legislações vigentes, por outro lado, o crescimento urbano desordenado é reconhecidamente um fator de degradação ambiental e de diminuição do equilíbrio ecológico. Dessa forma, torna-se um desafio cumprir a lei no espaço urbano da cidade de Patos, se não for exercitada, na práxis, deixando brechas para o não cumprimento dessas leis, aumentando, cada vez mais, o processo de degradação dos recursos naturais, trazendo problemas a curto e longo prazo. Sabe-se que a efetivação dessa delimitação irá gerar conflitos com aqueles que fazem o uso inapropriado das margens dos rios. No entanto, cabe aos órgãos locais efetivarem o cumprimento da legislação. 
De acordo com Sepe et al. (2014), não houve tempo para discussão sobre as regras de proteção desses espaços em áreas urbanas, contudo, as cidades se desenvolveram e se desenvolvem legalmente e ilegalmente sobre as porções do território que o Novo Código Florestal visa proteger, pois atualmente existe, em boa parte das cidades brasileiras, ocupação consolidada, praticamente impossível de se reverter.

São vários os programas e projetos assegurando a preservação das APPs, tanto em leis federais como estaduais e municipais. Na Constituição federal, em seu artigo 30, incisos I e II do texto constitucional, determina-se:

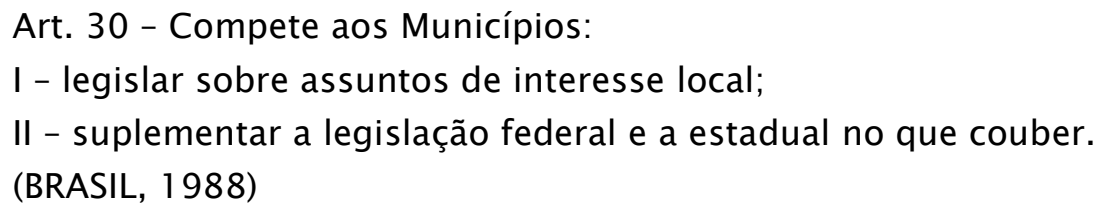

Portanto, o município tem competência administrativa em comum com a União e o Estado e também a competência legislativa concorrente com esses entes federativos. Dessa forma, é papel do Município promover ações que minimizem os problemas de natureza socioambiental dentro do seu espaço territorial, como é o caso específico das APPs, visto que estão contidos dentro de limites territoriais das cidades, cuja proteção deve ser de interesse da população local e daqueles que indiretamente dependem disso, que é a população residente à jusante desse território.

O Código Florestal Estadual visa proteger e recuperar as APPs, como descreve em seu artigo $3^{\circ}$ : "Promover a recuperação de áreas degradadas especialmente nas áreas de preservação permanente, reserva legal, entorno das unidades de conservação, bem como proteger as áreas ameaçadas de degradação [...]" (PARAÍBA, Lei n 6.002, de 29 de dezembro de 1994).

No capítulo segundo da referida lei, que trata da exploração e reposição florestal, de acordo com o Art. $6^{\circ}$, "toda exploração florestal no Estado dependerá de prévia autorização do órgão competente" (PARAíBA, Lei $n^{\circ} 6.002$, de 29 de dezembro de 1994)

O Plano Diretor do município deixa bem claro a respeito das Áreas de Preservação, no art. $30^{\circ}$, inciso XVIII, que é objetivo da lei "impedir a ocupação das margens dos rios, barragens e açudes por habitações irregulares, com monitoramento e vigilância, com comunicações, com as associações de moradores de bairros e das áreas ribeirinhas" (PATOS, Lei ${ }^{\circ}$ 3.503, de 06 de outubro de 2006). O que se vê é o não cumprimentos dessas 
leis, pois, na cidade de Patos, os órgãos, tanto estaduais como municipais, são omissos, deixando acontecer as ocupações irregulares nas APPs.

Conforme Medeiros (2011), atividades antrópicas acompanhadas da falta de consciência e informação por parte da população, ausência de fiscalização e a omissão dos poderes públicos são fatores que colaboram significativamente para o aumento dos processos de degradação das bacias.

A proposta de delimitação irá servir de base para os futuros projetos de revitalização e para uma tentativa de, pelos menos, aproximar a área delimitada proposta pela SUDEMA ao cumprimento da lei de uso e ocupação do solo, pois é sabido que a cidade de Patos ainda não dispõe de um mapa do Rio Espinharas delimitando sua calha e APPs. Com isso, os órgãos competentes devem tomar medidas cabíveis e analisar cada caso em particular para resolver a questão das pessoas que vivem ou ocupam as APPs nas margens do Rio Espinharas.

O importante é que agora há uma proposta real de delimitação para ser discutida pelos órgãos competentes e a sociedade "patoense", podendo, assim, conter, a partir de agora, novas invasões, e restaurar e/ou recuperar as áreas degradadas dentro das possibilidades, tendo em vista que há locais em que este processo é quase que irreversível, devido ao alto custo em liberar as áreas ocupadas por grandes empreendimentos e um número significativo de residências.

\section{Considerações finais}

Diante das condições e com base nas observações anteriores, constata-se que são vários os problemas ambientais encontrados no Rio Espinharas, no perímetro urbano da cidade de Patos, sendo os principais a eliminação da mata nativa, a eutrofização, o assoreamento e a poluição (resíduos líquidos e sólidos). Esses problemas estão associados, principalmente, ao descaso da população e ausência dos poderes públicos, tanto na fiscalização dos órgãos competentes como na realização de obras de infraestrutura.

A delimitação de APPs em rios urbanos é bastante complexa, devido às margens dos rios estarem bastante antropizadas, como é o caso do Rio Espinharas, na cidade de Patos, em seu perímetro urbano, pois mesmo que as APPs tenham amparo nas leis federais, estaduais e municipais para evitar a sua ocupação, as mesmas estão sendo ocupadas por ambas as classes 
sociais, até mesmo órgãos estaduais, ocorrendo descumprimento da legislação e a falta de fiscalização e omissão dos órgãos competentes, contribuindo para este processo.

A população ribeirinha é uma das principais causadoras dos impactos e, por outro lado é também aquela que sofre com os impactos causados por ela mesma. Não se percebem ações efetivas que poderiam contribuir com a mobilização das pessoas e/ou órgãos responsáveis por mudanças que viessem a reverter o processo de degradação já consolidada.

É preciso uma ação conjunta dos poderes públicos, da população, dos empresários, enfim, de todos que compõem a sociedade "patoense" contribuindo para a redução dos impactos que assolam o Rio Espinharas, bem como para sua recuperação e/ou restauração.

\section{REFERÊNCIAS}

AESA. Agência Executiva de Gestão das Águas do Estado da Paraíba. Plano Estadual dos Recursos hídricos do Estado da Paraíba. Relatório Final. Ano hidrológico 2008-2009. 2009. Disponível em: <aesa.pb.gov.br > Acesso em: 01 de nov. 2014.

ALMEIDA, L. Q. Vulnerabilidades socioambientais de rios urbanos: bacia hidrográfica do Rio Maranguapinho, Região Metropolitana de Fortaleza, Ceará. Tese (doutorado). - Universidade Estadual Paulista, Instituto de Geociências e Ciências Exatas, Rio Claro, 2010. Disponível em: < http://www.periodicos.capes.gov.br/>. Acesso em: 12 nov. 2014.

ALMEIDA, L. Q.; CARVALHO, Representações, riscos e potencialidades de rios urbanos: análise deum (des) caso histórico. Caminhos de Geografia. v.11, n.34, set/2007, p.145-161.

AQUINO, L. L. Geografia Patos: bases para compreensão do Espaço. Patos PB, 2011.

ARIZA, C. G.; SANTOS, D. G. Qualidade Ambiental e Planejamento Urbano. Caminhos de Geografia, v.9, n.26, p 224-242, junho/2008.

AZEVEDO, R. E. S.; OLIVEIRA, V P. V. Reflexos do novo Código Florestal nas Áreas de Preservação Permanente - APPs - urbanas. Desenvolvimento e Meio Ambiente, v. 29, p. 71-79, abr. 2014. 
BRANCO, S. M. Água: Origem, uso e preservação. 2 ed. São Paulo, Moderna 2003.

BRASIL. Constituição (1988). Constituição da República Federativa do Brasil. Brasília, DF: Senado, 1988.

------. Lei dos Crimes Ambientais (1998). Lei n 9.605 de 12 de fevereiro de 1998.

Novo Código Florestal (2012). Lei $n^{\circ} 12.651$ de 25 de maio de 2012.

Politica Nacional dos Recursos Hídricos (1997). Lei n 9.433 de 08 de janeiro de 1997.

Política Nacional do Meio Ambiente (1981). Lei $n^{\circ}$ 6.938, de 31 de agosto 1981.

CATARINA,T. Percepção sócio-ambiental e histórico no entorno do Rio Espinharas, na zona urbana de Patos-PB. 2003. 49f. (Monografia). Unidade Acadêmica de Engenharia Florestal. UFG, 2003.

COELHO, M. C. N. Impactos ambientais em áreas urbanas - Teorias, Conceitos e Métodos de Pesquisa. In: GUERRA, A. J. T. \& CUNHA, S. B (orgs): Impactos Ambientais Urbanos no Brasil. Rio de Janeiro: Bertrand Brasil, p. 1945, 2001.

CONAMA. Resolução 001 de 23 janeiro de 1986. Dispõe sobre critérios básicos e diretrizes gerais para o Relatório de Impacto Ambiental - RIMA. Disponível em: $<$ http://www.mma.gov.br/port/conama/legiabre.cfm?codlegi=23>. Acesso em: 11 out. 2014.

CHRISTOFOLETTI, A. Geomorfologia Fluvial. São Paulo: Edgard Blücher, 1981. DAMIS, R.C.B.; ANDRADE, T.S. A inaplicabilidade do Código Florestal em área urbana. Revista Brasileira de Direito Ambiental - v. 2 n 8, pp.121-143, out./ dez. 2006. 
GONÇALVES, A. B. et al. Mapeamento das Áreas de Preservação Permanente e identificação dos conflitos de uso da terra na sub-bacia hidrográfica do Rio Camapuã/Brumado. Revista Árvore, Viçosa-MG, v. 36, n. 4, p. 759-766, 2012.

IBGE. 2014. Disponível em: <http://www.ibge.gov.br/home/> Acesso em: 13 nov. 2014.

IBGE. 2010. Pesquisa Nacional de Saneamento Básico 2008. Disponível em: <http://www.ibge.gov.br/home/> Acesso em 14 nov. 2014.

IPAM. 2014. Instituto de Pesquisa Ambiental do Amazônia. Código Florestal, por um debate pautado em Ciência. Disponível em <http://ipam.org.br/> Acessa do em: 23 de jan. 2015.

MACIEL, M. A. As áreas de preservação permanente em área urbana: $O$ aparente conflito entre o Código Florestal e a Lei de Parcelamento do Solo. In: Âmbito Jurídico, Rio Grande, XIII, n. 83, dez 2010. Disponível em: $<$ http://www.ambitojuridico.com.br/site/index.php?n_link=revista_artigos_l eitura\&artigo_id=8703>. Acesso em: jan 2015.

MACHADO, P. A. L. Legislação Florestal (Lei 12.651/2012) e Competência e licenciamento ambiental (Lei complementar 140/2011). $1^{\text {a }}$ ed.. São Paulo. Cicacor Editorial, 2012.

MEDEIROS, S. S., et al. Estudo da degradação ambiental nas bacias hidrográficas do estado da Paraíba. In: Giovanni Seabra; Ivo Mendonça. (Org.). Educação Ambiental: responsabilidade para conservação da sociobiodiversidade. João Pessoa: Editora Universitária da UFPB, 2011 , v. 02, p. 669-673.

MIRANDA, A. H. M. APP em Área Urbana Consolidada. In: JARCOMINO, S.(EE.). Boletim Eletrônico IRIB. São Paulo. Ano VII, 2008, p.01-25. 
MUCELIN, C. A., BELLINI, L. M. Lixo e impactos ambientais perceptíveis no ecossistema urbano. Sociedade \& Natureza, Uberlândia, 20 (1), p. 111-124, jun. 2008.

PATOS, Plano diretor e Desenvolvimento Integrado. Lei $n^{\circ} 3.503$ de 06 de outubro de 2006. Define o Plano Diretor e Desenvolvimento Integrado do Município de Patos, e dá outras providências. Disponível em $<$ http://leis.camarapatos.pb.gov.br/files//2006/3.503-2006.pdf $>$. Acesso em: 21 de jan. 2015.

Código do Meio Ambiente. Lei n³.486 de 09 de maio de 2006.

PARAÍBA, Código Florestal. Lei n 6.002 de 29 de dezembro de 1994. Dispõe sobre a Política Florestal do Estado.

PINHEIRO, M. V. Avaliação técnica e histórica das enchentes em Itajubá - MG. 2005. 104 p. Dissertação (Mestrado em Engenharia de Energia) Universidade Federal de Itajubá, Itajubá, 2005.

RIBEIRO, C. A. A. S. et al. O desafio da delimitação de Áreas de Preservação Permanente. Revista Árvore, Viçosa-MG, v. 29, n. 2, p. 203-212, 2005.

SANTOS, H. G. et al., Sistema Brasileiro de Classificação de Solos. 3 ed. ver ampl. Brasília, DF: Embrapa, 2013. 353 p. :il. Color. ; $16 \mathrm{~cm} \times 22 \mathrm{~cm}$.

SANTOS, A. R.; SCAGLIUSI, F. L. Áreas de Preservação Permanente (APPS) no ambiente urbano. A necessidade de uma legislação específica. Minha Cidade, São Paulo, ano 11, n. 126.05, Vitruvius, jan. 2011 <Disponível em:<http://www.vitruvius.com.br/revistas/read/minhacidade/11.126/3703 $>$.Acessado em: 21 jan 2015.

SEPE, P.M. et al., O novo Código Florestal e sua aplicação em áreas urbanas: uma tentativa de superação de conflitos?. In: $3^{\circ}$ Seminário Nacional sobre $o$ Tratamento de Áreas e Preservação Permanente em Meio Urbano e Restrições Ambientais ao Parcelamento do Solo. Belém, UFPA. Anais... Belém, UFPA, 2014. 
SOARES-FILHO, B. S. Impacto da Revisão do Código Florestal: como viabilizar o grande desafio adiante? Desenvolvimento Sustentável - Subsecretaria SAE (Secretaria de Assuntos Estratégicos) - Governo Federal. 28 p. 2013.

SUGUIO, K. Geologia sedimentar. São Paulo: Blucher, 2003.

TUNDISI, J. G. Água no Século XXI: Enfrentando a Escassez. São Carlos: Rima, IIE, 2003. 248p.

UNESCO. Compartilhar a água e definir o interesse comum. In: Águas para todos: água para a vida. Edições UNESCO, p.25-26. (Informe das Nações Unidas sobre o desenvolvimento dos recursos hídricos no mundo), 2003.

Submetido em 03/03/2016

Aprovado em 20/04/2016

Sobre os autores

João Batista Alves

Doutor, Professor no UAEF/CSTR/Universidade Federal de Campina Grande.

E-mail: alvesjb@uol.com.br

Felipe Silva de Medeiros

Eng.Florestal. Analista Ambiental da Superitendência de Administração do Meio Ambiente da Paraíba.

E-mail: fsmedeiros.eng@gmail.com 